\title{
Judgments of recency and their relation to recognition memory
}

\author{
DOUGLAS L. HINTZMAN \\ University of Oregon, Eugene, Oregon
}

\begin{abstract}
Subjects went through a list of 550 high- and low-frequency words (Experiment 1) or concrete and abstract words (Experiment 2) in which individual items were repeated at lags of 5 to 30 other items. They made old versus new recognition decisions on each word and followed each "old" response with a numerical judgment of recency (JOR). Recognition judgments displayed the mirror effect. Conditionalized on recognition, JORs were shorter for low-frequency words than for high-frequency words, and shorter for concrete words than for abstract words. This was true at every lag, suggesting that recognition and JOR may have a common basis. However, recognition confidence ratings obtained in Experiment 3 proved much less sensitive than JOR to test lag. Memory models applicable to multiple judgment tasks will be needed to account for such findings.
\end{abstract}

Relative to other memory tasks, judgment of recency (JOR) has received little attention from researchers. This neglect is ironic because apparent recency was a focus of one of the first mechanistic memory models (Hooke, 1969; see also Hintzman, in press) and because several threads of evidence suggest that recency discrimination may be fundamental to performance in other memory tasks.

One such thread concerns what are called long-term recency effects in the serial position curve of free recall. Using the continuous distractor paradigm, which increases the times between study presentations of words, Bjork and Whitten (1974) found that the recency part of the free recall curve can extend beyond the purported duration of short-term memory. A prominent account of this result is the ratio rule, which states that the recency advantage is a function of the ratio of the interitem interval to the retention interval (Bjork, 2001; Bjork \& Whitten, 1974; Crowder, 1976; Glenberg, Bradley, Kraus, \& Renzaglia, 1983; Glenberg \& Swanson, 1986). Further explication of this rule often invokes a process of "temporal distinctiveness." Oddly, however, the literature on long-term recency effects does not seem to reference the literature on JOR, which might be seen as a fairly direct way to measure temporal distinctiveness. It is interesting that the discrimination of recencies follows an approximately logarithmic function, in which constant ratios yield constant levels of discrimination performance (Hinrichs, 1970; Yntema \& Trask, 1963; see also Hintzman, 2000). So the ratio rule appears generally consistent with JOR data.

A second thread of evidence implicates relative recency in the Brown-Peterson short-term memory task. In a classic study, Keppel and Underwood (1962) did not find rapid

Correspondence should be addressed to D. L. Hintzman, Department of Psychology, University of Oregon, Eugene, OR 97403 (e-mail: hintzman@oregon.uoregon.edu). forgetting on the first trial of their experiment. Instead, the rate of forgetting increased over the first few trialsa result that was attributed to proactive inhibition or interference (PI). Indeed, intrusion errors in this task are most likely to come from immediately preceding trials, just as the PI hypothesis would predict. Further research showed that PI diminishes as the intertrial interval becomes longer (Kincaid \& Wickens, 1970; Loess \& Waugh, 1967; Peterson \& Gentile, 1965). That is, the greater the age of the presentation on the previous trial, the less interference it causes on the current trial. These results suggest that something like the ratio rule may operate in the BrownPeterson task (for a review, see Greene, 1992). As one researcher pointed out, the Brown-Peterson subject's job "is to report the most recently presented item. This task description makes it reasonable to assume that one component of retrieval corresponds to making a recency judgment" (Bennett, 1975, p. 140).

A third thread of evidence-leading most directly to the present experiments-implicates recency discrimination in recognition memory. Formally, the subject's task in a recognition-memory experiment is to discriminate items that have been presented in a particular context (e.g., on the screen of a computer in a particular experimental room) from items that have not been presented in that context. Almost always, however, the test list is given immediately after the study list, so the task could equally well be described as one of identifying test items that are more recent than the study list's onset. It is not uncommon to give the same subjects repeated cycles of study and test lists in what is objectively the identical context, with the understanding that recognition judgments relate only to the immediately preceding list. In the case of certain withinsubjects manipulations - for example, the investigation of list-length and list-strength effects (Ratcliff, Clark, \& Shiffrin, 1990; Shiffrin, Ratcliff, \& Clark, 1990)-it becomes theoretically important to assume that subjects restrict re- 
trieval to the most recent study list with fairly high accuracy, because the manipulation of interest is counterbalanced over a succession of lists. (For a detailed discussion of implications of this assumption for modeling the list-length and list-strength effects, see Murdock \& Kahana, 1993a, 1993b; Shiffrin, Ratcliff, Murnane, \& Nobel, 1993).

The most direct test of the assumption that recognition subjects can restrict access to the most recent list is to require them to respond "new" to test items that have not occurred in the study list, but that have occurred in an earlier list in the same context. False alarm rates to such items increase directly with the number of prior occurrences in the experimental context (Maddox \& Estes, 1997), suggesting that recency discrimination in recognition is far from perfect. In a variation on recognition memory known as list discrimination, subjects must not only distinguish old items from new items, but also judge the list membership of old items. List-discrimination data suggest a twostage retrieval process in which subjects are aware that an item has occurred previously in the experiment before they can accurately judge its list membership (Hintzman, Caulton, \& Levitin, 1998). There is evidence that list discrimination is sensitive to relative recency in roughly the way predicted by the ratio rule; that is, the longer the interval that separates lists, the better list discrimination is, but this advantage disappears as the retention interval becomes longer (Hintzman \& Waters, 1969).

If recency judgment represents a fundamental memory process, it is desirable to measure it as directly as possible. Accordingly, two additional considerations guided the designs of the present experiments. First, it is important to distinguish between judgments of recency and judgments of serial position. Judgments of serial position relate to a list or series of events having a well-defined beginning and end. Position-judgment accuracy displays strong primacy effects as well as recency effects (Hintzman, Block, \& Summers, 1973). These primacy effects-and the recency effects, to a smaller extent-may reflect associations with unique contextuallandmarks. The present task followed Yntema and Trask (1963) and Hinrichs and Buschke (1968) in attempting to create a "steady state" in which such landmarks are absent. Subjects were required to discriminate a relatively short range of recencies in a long continuous list.

Second, it makes little sense to ask a subject to judge the recency of an item if the subject believes the item is new. Accordingly, subjects first made "old" versus "new" recognitionjudgments and made subsequent JORs only to items they had identified as old. The task can be characterized as continuous recognition with contingent recency judgment. (For previous experiments using this paradigm, see Hintzman, 2001, 2002.)

Here, the just described task was used to explore the relation between recognition memory and recency judgments, in the effects of item variables known to produce mirror effects in recognition memory. In particular, highfrequency $(\mathrm{HF})$ words generally yield lower hit rates and higher false alarm rates than do low-frequency (LF) words, and abstract words yield lower hit rates and higher false alarm rates than do concrete words (e.g., Glanzer \& Adams, 1985). Word frequency was manipulated in Experiment 1, and concreteness was manipulated in Experiment 2 . The results raised an additional question of how JORs compare with recognition confidence ratings. To answer this question, a third experiment was done, in which "old" judgments were followed not by JORs, but by confidence ratings.

Of primary interest are the effects of word frequency and concreteness on JORs. One way to think of the mirror effect is that memories of old LF or concrete words are somehow "stronger" than memories of old HF or abstract words. If this is the case, then one might expect LF words to seem more recent than HF words, and concrete words to seem more recent than abstract words, at every level of recency.

An alternative way to think of the mirror effect is that it exemplifies a more general rule: All kinds of episodicmemory judgments are more accurate for LF and concrete words than for the contrasting categories. In the case of old-new recognition, the judgments are more accurate when the word is old and also more accurate when the word is new. Errors in JOR tend to be overestimates at short lags and underestimates at long lags. So if JORs for LF words are more accurate than those for HF words, the JOR function for LF words should begin below, and cross over, the function for HF words. Mean JORs for concrete and abstract words should display a similar pattern.

Previous studies do not appear adequate to answer this question. Yntema and Trask (1963) had subjects judge the relative recencies of pairs of words and found greater accuracy on concrete words than on abstract words. However, there were no mixed-pair tests because the two word types occurred in separate lists. Also, the judgments could have been differentially influenced by recognition failure because subjects were not given the option of indicating that a test word was new. Fozard and Weinert (1972) used a mixed-list design to compare numerical JORs for pictures with those for nouns. Median JORs for pictures were lower (more recent) than those for nouns at short recencies, but about the same at longer recencies. Nonrecognized items were excluded from JORs. However, item recencies were not counterbalanced, and items studied near the beginning of the list were included in the analysis, which leaves a possible role for contextual landmarks.

Other studies have used shorter lists. In an experiment by Wells (1974, Experiment 2), JORs for nonsense syllables (CVCs) crossed over those for less memorable consonant trigrams (CCCs). However, Wells used 12-item study lists and required a JOR except when the subject reported the highest confidence that the test item was new. Greene (1996, Experiment 2) had subjects discriminate relative recencies of word-word, nonword-nonword, and wordnonword pairs and found judgment accuracy to be greater for words than for nonwords. Greene (1996) used 28-item study lists and did not give subjects the option of indicating that a test item was new. Using 9-item lists, Mulligan (2001) compared performance on LF and HF words in three different tasks: recognition, order reconstruction, and re- 
cency discrimination. The superiority of LF to HF words in recognition was reversed in the order-reconstruction task, and there was no apparent HF-LF difference in recency discrimination. Although the item variables in the Wells, Greene, and Mulligan experiments relate to mirror effects in recognition memory, the findings are of questionable relevance to steady-state JOR because of the short study lists. List beginnings provide likely contextual landmarks when repeated study-and-test cycles are used.

\section{EXPERIMENTS 1 AND 2}

\section{Method}

Subjects. University of Oregon undergraduates participated for course credit. There were 18 subjects in Experiment 1 and 31 in Experiment 2 .

Materials. Mutually exclusive word pools were used in Experiments 1 and 2. All words were English nouns. Concreteness ratings were based on a 1-7 scale, and nominal frequencies were word counts per million from Kučera and Francis (1967). The word pool for Experiment 1 consisted of $170 \mathrm{HF}$ and $170 \mathrm{LF}$ nouns, 4-8 letters in length, and the word pool for Experiment 2 consisted of 187 concrete words and 187 abstract words, 4-9 letters in length. Table 1 gives mean values for concreteness, frequency, and word length.

Procedure. The procedures of both experiments followed that of Hintzman (2002). The subjects were tested individually. They were seated before a Macintosh IIci computer controlling a full-page monitor and were told that they would see a long list of words in which many words would be repeated. Their first task was to decide whether each word was new or old in the list by pressing the "Z" or the "?/" key on the keyboard. If they decided a word was old, they would also be asked to judge how far back in the list the word had occurred previously. They were told that a word could be repeated after $5,10,15,20,25$, or 30 intervening items, and that the JORs, or lag judgments, were to be made using the 1-6 keys of the numerical keypad, which had been relabeled with the appropriate numbers. The subjects were told they should rely on their intuitive feelings of recency because there was no reasonable strategy for keeping track of word order.

The experimental list was 550 items long. The program stepped through positions $\mathrm{P}=1-550$, in sequence. It began by randomly selecting a word from the pool, choosing 1 of 6 repetition lags at ran$\operatorname{dom}($ lag $=5,10,15,20,25$, or 30), and assigning the word to both $\mathrm{P}=1$ and $\mathrm{P}=1+\operatorname{lag}$. Beyond $\mathrm{P}=2$, the program first checked to see whether an old word had already been assigned to P. If not, a new word was assigned to $\mathrm{P}$, one of the six values of lag was chosen at random, and the second presentation of the word was assigned to $\mathrm{P}+$ lag. If $\mathrm{P}+\operatorname{lag}$ was already occupied by an old word, a new value of lag was randomly generated. If this second attempt failed to select an unoccupied value of $\mathrm{P}+$ lag, the word was not repeated in the list. Data were analyzed for test positions $32-550$ only. This scheme resulted in a mean of 20.8 observations per condition (lag $\times$ item type) per subject.

A 500-msec blank interval preceded the onset of each test word, which was displayed in 48-point lowercase Helvetica font in the center of the screen. When the word appeared, the subject first was asked to indicate whether it was old or new. The response alternatives (" $\mathrm{Z}=$ new" and "?/ = old") were shown beneath the word in a single line. If the subject responded "old," this instruction was immediately replaced by the two lines: "How many items back?" and "5 1015202530 ." Each display remained on the screen until the subject responded. Illegal keypresses resulted in a warning and a repeated request for a response. The subjects were told to go through the list at their own pace. This typically took around $30 \mathrm{~min}$ - about $3 \mathrm{sec}$ per item.

\section{Results}

To ensure that analyses would reflect motivated performance, a dual criterion was established for retaining a given subject's data. The recognition hit rate had to be at least .70, and the correlation of mean JOR with lag had to be at least .70. Two subjects in Experiment 1 failed to meet the hit rate criterion, and computer problems disrupted the test session of another. Data from these 3 subjects were dropped from further analysis, leaving $N=15$. The retained subjects had a mean hit rate of .92 $(S D=.03)$ and a mean JOR-lag correlation of $.89(S D=.06)$.

Four subjects in Experiment 2 failed the hit rate criterion, and 2 others failed the JOR criterion. These 6 subjects' data were also dropped, leaving $N=25$. The retained subjects had a mean hit rate of $.90(S D=.07)$ and a mean JOR-lag correlation of $.89(S D=.03)$.

Recognition. False alarm rates in both experiments displayed the differences that characterize the mirror effect. In Experiment 1, the false alarm rate for $\mathrm{HF}$ words $(.052)$ was higher than that for LF words (.032) $[t(14)=6.22]$; and in Experiment 2, the false alarm rate for abstract words (.038) was higher than that for concrete words (.029) $[t(24)=$ $3.83]$. The overall difference in false alarm rates between the two experiments was not statistically reliable $(t<1)$.

Mean hit rates for the two experiments are displayed in Figure 1. Performance dropped slightly with lag, and hit rates showed the mirror effect pattern (LF $>\mathrm{HF}$ and concrete $>$ abstract) in both experiments. This difference appeared to be minimal at Lag 5 and to increase with increasing lag.

Hit rates were analyzed using planned-contrast $t$ tests, as outlined by Rosenthal and Rosnow (1985, pp. 56-62). Contrast coefficients were specified for lag (a linear function), item type, and the interaction between lag and item type. In Experiment 1, the effects of lag $[t(14)=3.95]$ and word frequency $[t(14)=4.33]$ and their interaction $[t(14)=$ 2.57] were all reliable. In Experiment 2, the effect of lag was reliable $[t(24)=3.27]$, as was its interaction with concreteness $[t(24)=2.26]$, but the main effect of concreteness reached only marginal significance $[t(24)=1.83$, twotailed $p=.088]$.

Hit rates were significantly higher in Experiment 1 than in Experiment $2[t(38)=2.35]$, although it is not obvious why. The word pools were of course different, but Experiment 1 was also conducted earlier than Experiment 2 in the academic term, so the subject pools may also have differed in motivation or ability.

JOR. Mean JORs, conditionalized on recognition, are shown in Figure 2. JORs were shorter in Experiment 1 than in Experiment 2, a nonsignificant difference $[t(38)=$

Table 1

Mean Statistics for the Word Pools Used in Experiments 1-3

\begin{tabular}{lccc}
\hline Word Category & Concreteness & Frequency & Length \\
\hline High frequency & 5.1 & 183.3 & 6.0 \\
Low frequency & 5.2 & 1.4 & 6.1 \\
Concrete & 6.8 & 52.7 & 6.5 \\
Abstract & 4.5 & 54.0 & 6.5 \\
\hline
\end{tabular}



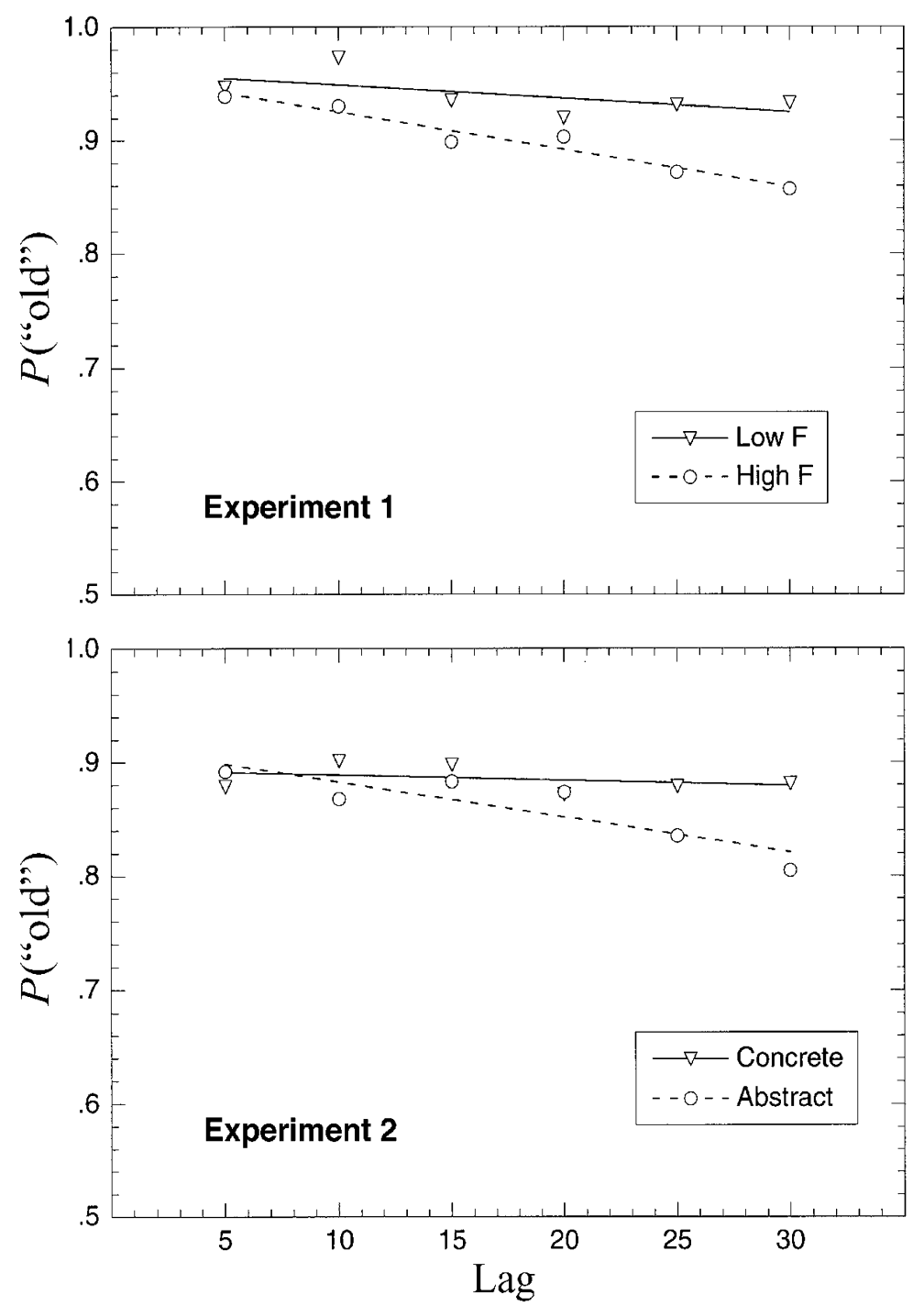

Figure 1. Recognition hit rates for Experiment 1 (top panel) and Experiment 2 (bottom panel). Low F, low frequency; High F, high frequency. Average $S E=.017$ for Experiment 1 and $\mathbf{0 2 2}$ for Experiment 2. Linear functions fitted to the data.

1.83], but otherwise results from the two experiments appear similar. In both cases the condition yielding better recognition also had shorter JORs, a difference that diminished somewhat with increasing lag.

Statistical evaluation of the JORs was done in the same way as it was for recognition. The effect of lag was highly reliable in both experiments $(t>6.0)$. In Experiment 1 , the main effect of word frequency and its interaction with lag were both significant $[t(14)=4.25$ and 2.83 , respectively]. In Experiment 2, the main effect of concreteness was significant $[t(24)=3.72]$ and its interaction with lag was marginally significant $[t(24)=2.07, p=.057]$. In neither case was the interaction manifested in a crossing of the curves. A gradual convergence of mean JORs defined both of the interactions.

For comparison with the JORs on recognition hits shown in Figure 2, mean JORs on false alarms averaged
24.7 on HF words and 23.7 on LF words (Experiment 1), and 21.5 on concrete words and 21.2 on abstract words (Experiment 2). Neither difference was reliable $(t<1)$.

\section{Discussion}

These results offer no support for an interpretation of the mirror effect in which all episodic memory judgments are more accurate for $\mathrm{LF}$ words than for HF words, and more accurate for concrete words than for abstract words. Greater JOR accuracy over the entire range of lags would require the higher accuracy curve to begin below and to cross over the lower accuracy curve. Instead, the data are consistent with the idea that JORs are based on some kind of strength or familiarity, which is higher for old items in the better recognized category.

Nevertheless, it does not appear that the quantity underlying JORs can be the same as the one underlying recog- 

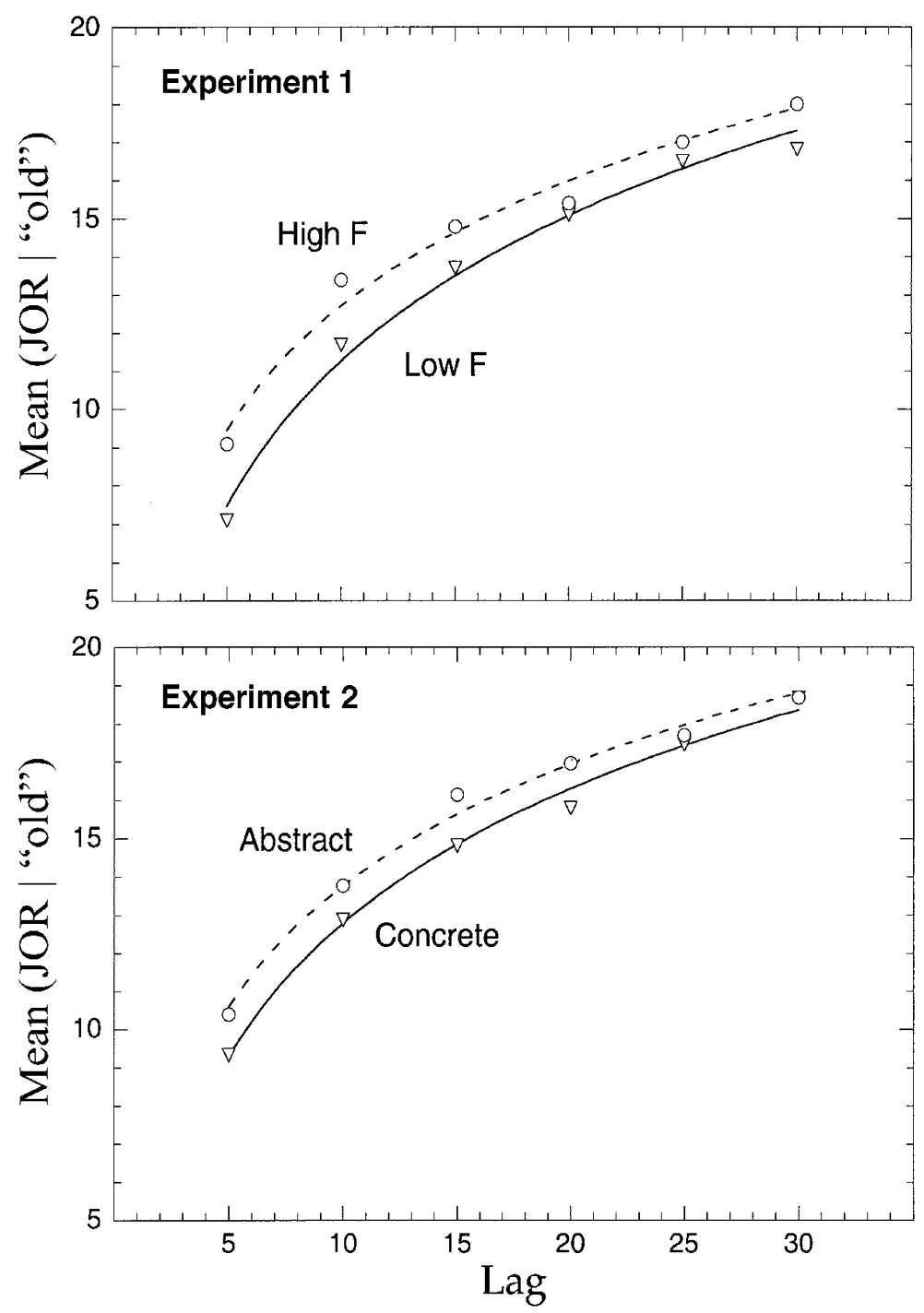

Figure 2. Mean judgment of recency (JOR) given correct recognition for Experiment 1 (top panel) and Experiment 2 (bottom panel). High F, high frequency; Low F, low frequency. Average $S E=0.72$ for Experiment 1 and 0.44 for Experiment 2. Log functions fitted to the data.

nition judgments. This can be seen by comparing the sizes of the effects of the two independent variables on the two types of judgment. For easy quantitative comparison, Table 2 shows the proportions of variance among means explained by linear regression on lag and word type $\left(r^{2}\right)$. In both experiments, mean JOR was much more affected by lag than by word type. Contributions of lag and word type to $P$ ("old") were more balanced.

In spite of these differences, there are two ways that a determined skeptic might maintain the hypothesis that JORs and recognition judgments are based on the same quantitative information. One is to appeal to the sequential ordering of the tasks: The old-new decision was made first and the JOR followed. Assessment of retrieved strength might become more precise in the 1 or $2 \mathrm{sec}$ that separated the two judgments. The other way is to argue that old-new judgments and JORs reflect different regions of the same strength distribution. That is, the recognition hit rate reflects the proportion of strengths falling below a particular criterion, whereas the JOR reflects differentiation

Table 2

Proportions of Variance Among Means Explained by Regression on Lag and Word Category

\begin{tabular}{clcc}
\hline & & \multicolumn{2}{c}{ Independent Variable } \\
\cline { 3 - 4 } Experiment & Measure & Test Lag & Word Type \\
\hline 1 & $P$ (“old") & .39 & .42 \\
& JOR & .85 & .03 \\
2 & $P$ (“old") & .35 & .25 \\
& JOR & .91 & .02 \\
3 & $P$ (“old") & .06 & .45 \\
& Confidence & .12 & .73 \\
\hline
\end{tabular}

Note—P("old"), recognition hit rate; JOR, judgment of recency. 
among strengths that are above the criterion. Experiment 3 was designed to deal with these arguments by obtaining a measure of recognition more directly comparable to the JORs from Experiment 1.

\section{EXPERIMENT 3}

In order to minimize ambiguity about differences between JOR and recognition judgments, Experiment 1 was repeated with a single change: The JOR task was replaced by recognition confidence ratings. Following each "old" response, subjects used a 3-point scale to rate their confidence in the response. Consistent with Experiment 1, "new" responses were not followed by a rating. To discourage subjects from always giving the highest confidence rating and to tie the ratings to an objective measure of performance, subjects were encouraged to think of their ratings as gambles in which they would gain points if the test word really was old and lose points if it was new. The rewards associated with old items and the costs associated with new items increased across the Ratings $1-3$, but the cost function was steeper.

\section{Method}

Subjects and Materials. Twenty subjects were recruited as they had been in Experiments 1 and 2, and were tested individually. The word lists were drawn from the pool of HF and LF words used in Experiment 1 .

Procedure. The procedure followed that of Experiment 1 except that the request for a JOR following each "old" response was replaced by the request for a numerical confidence rating $(1,2$, or 3$)$. The subjects were told to think of the ratings as gambles with which they could gain or lose points. For each rating of " 1 ," they would gain 1 point if the test word was old and lose 1 point if it was new; for each rating of " 2 " they would gain 2 points if the word was old and lose 5 points if it was new; and for each rating of " 3 " they would gain 5 points if the word was old and lose 50 points if it was new. As a reminder, whenever the experimental program requested a confidence rating, these rewards and costs (e.g., " 2 = win 2 lose 5") were displayed in three rows beneath the test word.

"New" responses had no effect on the point total. The subjects were told that they began the list with 0 points, and that their point total would be displayed at the end of the experiment. In all other respects the procedure was identical to that of Experiment 1.

\section{Results and Discussion}

No subjects' data were eliminated from analysis in Experiment 3 . All had recognition hit rates over $.70(M=$ $.90, S D=.07)$, and all appeared to have used the confidence scale in accordance with instructions. Overall, the posterior probability that an item was new was .275 , given confidence $=1 ; .087$, given confidence $=2$; and .007 , given confidence $=3$. Nineteen of the 20 subjects had higher false alarm rates at confidence $=1$ than at confidence $=3$-the exception being a subject who made only a single false alarm.

The top panel of Figure 3 shows the proportion of "old" judgments to old words (comparable to Figure 1), and the bottom panel shows the mean confidence ratings, conditional on a correct "old" judgment (comparable to JORs in Figure 2).
As in Experiment 1, observed values of $P$ ("old") in recognition conformed to the mirror effect. The false alarm rate was higher to HF words (.090) than to LF words $(.028)[t(19)=5.54]$. Planned contrasts showed also that the hit rate was lower to HF than to LF words $[t(19)=$ 2.76]. Neither the effect of $\operatorname{lag}[t(19)=1.57]$ nor its interaction with word frequency $[t(19)=1.42]$ was statistically reliable. The failure to replicate the interaction found in Experiment 1 was unexpected and seems best understood as a chance result. In any case, the discrepancies are far too small in percentage terms to meaningfully affect the conditional judgments.

Mean confidence, conditional on correct recognition of the test word as old, was lower for HF words than for LF words $[t(19]=6.06]$ and decreased as the lag increased $[t(19)=3.79]$. The interaction of word frequency with lag was not reliable $(t<1.0)$. For comparison with the values in Figure 3, mean confidence on false alarms was 1.50 for HF words and 1.33 for LF words, a nonsignificant difference $(t<1)$.

As was the case with mean JOR, mean confidence was affected by both lag and word frequency. However, the relative effect of lag on recognition confidence was much smaller than its effect on JOR (Table 2), suggesting that the two judgments depend on different properties of memory.

The most direct way to contrast the effect of lag on the two kinds of judgment is to transform both onto a common scale based on cumulative proportions. Figure 4 plots iso-rating curves derived from such an analysis. To simplify matters, this analysis aggregates data over HF and LF item types and also over subjects. To produce Figure 4, the proportions of JORs (Experiment 1) and confidence ratings (Experiment 3 ) exceeding successive criteria were calculated, as is routinely done to construct an ROC from confidence ratings. JOR $=5$ and confidence $=3$ defined the "highest strength" for the two judgment types. The other curves show the cumulative proportions exceeding successively more lenient criteria, as labeled in the figure. To limit graph clutter, all JORs $>15$ were combined into a single "weak item" response category, corresponding to the area above the highest JOR curve in the figure. As is apparent in Figure 4, the iso-JOR curves cross the isoconfidence curves. Relative to JOR, confidence was much less sensitive to lag. The curves could not cross in this way if a single quantity, declining with lag, determined both kinds of judgment.

\section{GENERAL DISCUSSION}

It was suggested earlier that the recognition mirror effect might be subsumed under a more general rule: that all episodic memory judgments are more accurate for LF and concrete words than for the contrasting categories. Experiments 1 and 2 offer no support for this characterization.JORs for the better recognized word category were systematically shorter, or more recent, than those for the contrasting category. So although these JORs were more accurate at short lags, which tend to be overestimated, they were less 

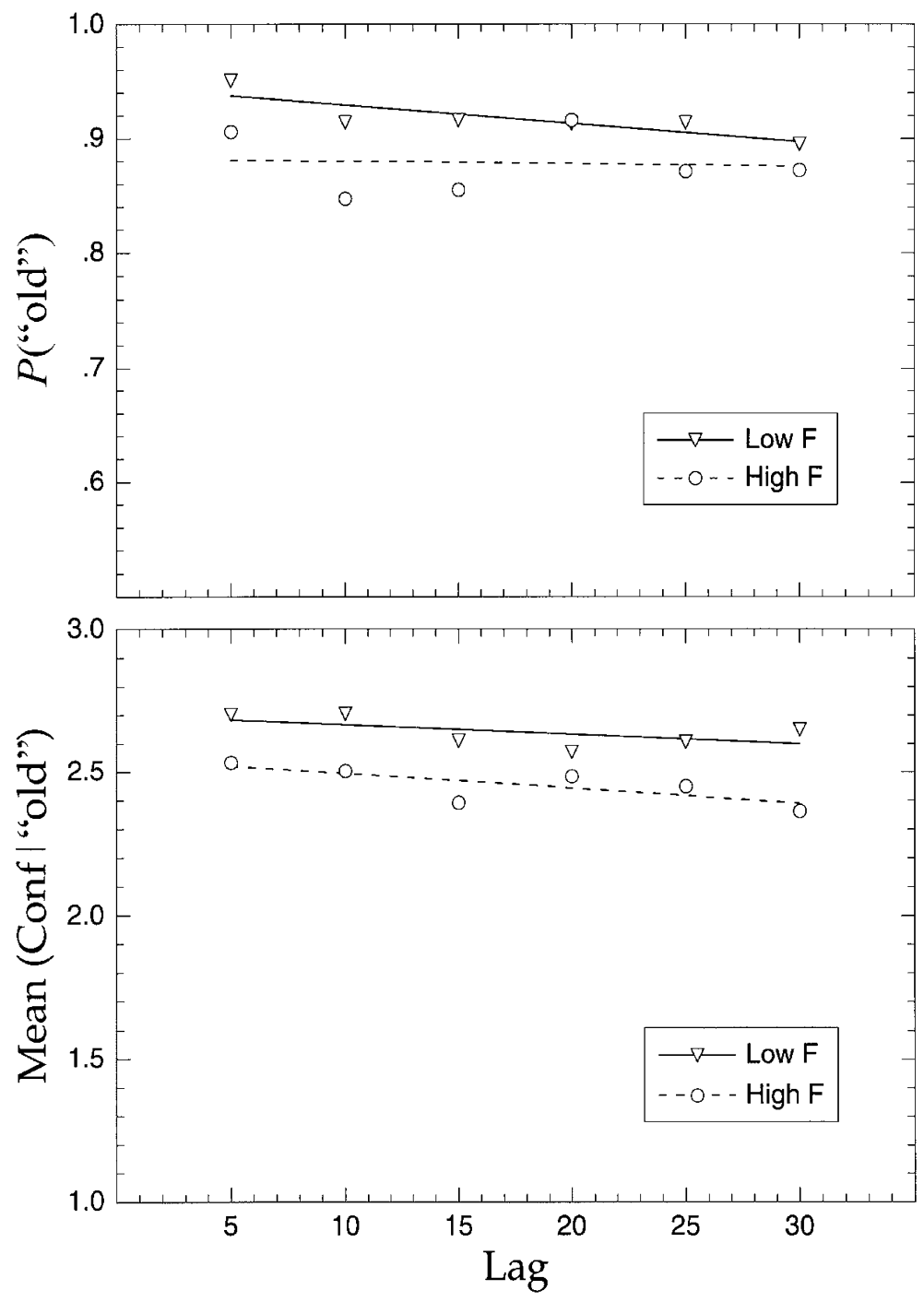

Figure 3. Results of Experiment 3. Top panel: recognition hit rates (average $S E=$ .022). Bottom panel: Mean judgment of recency (JOR) given correct recognition (average $S E=0.08$ ). Low $\mathrm{F}$, low frequency; High $\mathrm{F}$, high frequency. Linear functions fitted to the data.

accurate at long lags, which tend to be underestimated. The data are more consistent with the idea that memories of old items from the better recognized category are in some sense stronger, regardless of lag. Subjects gave JORs only to words that they recognized as old, so the difference in JORs is not a simple artifact of the difference in recognition.

Further evidence on the relation between JOR and recognition comes from a recent experiment on context matching (Hintzman, 2002). The task was the same as in the present Experiments 1 and 2, but individual items were presented in two distinct visual contexts, randomly determined. Thus a given item's test context either matched or mismatched its prior study context. Recognition hit rates were higher when the study and test contexts matched than when they were different. More importantly, mean JORs, conditional on recognition, were shorter at all lags when the study and test contexts matched than when they mismatched (the graph looked much like the ones in Figure 2).

This suggests that apparent recency depends not just on the strength of the trace but also on its match to the retrieval cue. In current memory models, trace activation is commonly assumed to be jointly determined by trace strength and cue-trace matching (e.g., Anderson, Bothell, Lebiere, \& Matessa, 1998;Hintzman, 1988; Murdock, 1982; Ratcliff, 1978; Shiffrin \& Steyvers, 1997), and recognition judgments are usually assumed to be based on trace activation.

Nevertheless, it will not be sufficient to simply take a trace-activation model of recognition and relabel it as a model of JOR (e.g., Murdock, Smith, \& Bai, 2001), be- 


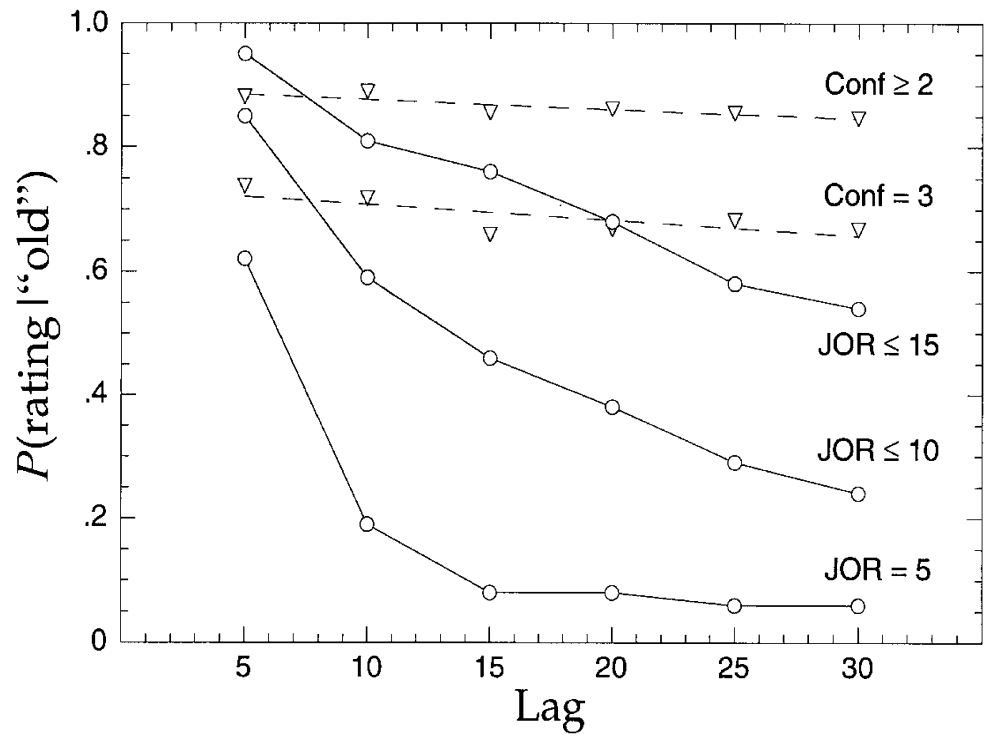

Figure 4. Iso-judgment of recency (JOR) curves from Experiment 1 and iso-confidence curves from Experiment 3, both conditionalized on correct recognition. Each point represents the proportion of responses exceeding a particular criterion.

cause — as the present data show—recognition judgments and JORs follow different patterns. Word frequency, concreteness, and lag affect performance on both tasks, but lag has a greater effect on JOR than it has on recognition. This conclusion is supported by comparison of the effects of lag and word type on recognition hit rate and mean JOR (Table 2), and by the observation that iso-JOR curves drop more rapidly than iso-confidence curves as a function of lag (Figure 4). Of course, this does not imply that recency discrimination plays no part at all in recognition judgments. It does suggest, however, that recognition judgments are based primarily on other kinds of information.

Taken at face value, the crossed iso-rating curves of Figure 4 suggest that subjects sometimes believe that a test word has been presented recently but are relatively uncertain that the word has actually been presented. This is not a direct contradiction because recency judgments and recognition judgments are answers to different questions; but it may nevertheless appear anomalous. An alternative possibility is that the recency belief-state and recognitionconfidence belief-state do not coexist in awareness, because the JOR and recognition tasks invoke different modes of retrieval. That is, a subject judging whether a test word is old may have no inkling of the word's recency. In this view, retrieval is not unitary-and it may not be sufficient to fractionate retrieval into familiarity and recollection. There may be several different kinds of retrieval, each of which activates a different kind of information.

The present dissociation between JOR and recognition confidence is similar to one reported earlier between JOR and remember versus familiar (or know) ratings (Hintzman, 2001, Experiment 2). The task was similar to the present one, but when subjects identified an item as "old" they were required to make two further judgments. First, they reported whether they remembered details of what had gone through their minds when they studied the word, or had judged the word "old" because it just seemed familiar. Second, they made a JOR. One finding was that "remembered" items were judged to be more recent than merely "familiar" items were. Another finding was that although the ratio of remember to familiar ratings declined as a function of recency or lag, remember versus familiar ratings did not discriminate among lags nearly as well as JOR did. A concern about the latter result was that it could have been an artifact of successive testing (i.e., subjects reporting whether or not they remember the item before they made a JOR). The present relation between JOR and recognition confidence, inferred from a comparison of Experiments 1 and 3, suggests that successive testing was not a crucial factor in the earlier study. The similarity between the two results also illustrates yet another way in which remember versus familiar ratings resemble recognition confidence ratings (see Donaldson, 1996).

Of course on intuitive grounds, the conclusion that JORs are especially sensitive to recency or lag is not surprisingsubjects are just following instructions. At the same time, however, the effects of word frequency and concreteness on JORs appear highly similar to their effects on recognition. The question is, how can the differences and the similarities between the two tasks be explained theoretically? An answer will require the development of models that can be applied to both JOR and recognition. The present data should be useful for testing such multitask memory models.

\section{REFERENCES}

Anderson, J. R., Bothell, D., Lebiere, C., \& Matessa, M. (1998). An integrated theory of list memory. Journal of Memory \& Language, 38, 341-380. 
Bennett, R. W. (1975). Proactive interference in short-term memory: Fundamental forgetting processes. Journal of Verbal Learning \& Verbal Behavior, 14, 123-144.

BJork, R. A. (2001). Recency and recovery in human memory. In H. L. Roediger III, J. S. Nairne, I. Neath, \& A. M. Surprenant (Eds.), The nature of remembering: Essays in honor of Robert G. Crowder (pp. 211-232).Washington, DC: American Psychological Association.

BJork, R. A., \& WhitTen, W. B. (1974). Recency-sensitive retrieval processes in long-term free recall. Cognitive Psychology, 6, 173-189.

Crowder, R. G. (1976). Principles of learning and memory. Hillsdale, NJ: Erlbaum.

Donaldson, W. (1996). The role of decision processes in remembering and knowing. Memory \& Cognition, 24, 523-533.

FozARD, J. L., \& WeINERT, J. R. (1972). Absolute judgments of recency for pictures and nouns after various numbers of intervening items. Journal of Experimental Psychology, 95, 472-474.

Glanzer, M., \& ADAms, J. K. (1985). The mirror effect in recognition memory. Memory \& Cognition, 13, 8-20.

Glenberg, A. M., Bradley, M. M., Kraus, T. A., \& Renzaglia, G. J. (1983). Studies of the long-term recency effect: Support for a contextually guided retrieval hypothesis. Journal of Experimental Psychology: Learning, Memory, \& Cognition, 9, 231-255.

GlenberG, A. M., \& Swanson, N. (1986). A temporal distinctiveness theory of recency and modality effects. Journal of Experimental Psychology: Learning, Memory, \& Cognition, 12, 3-24.

Greene, R. L. (1992). Human memory: Paradigms and paradoxes. Hillsdale, NJ: Erlbaum.

Greene, R. L. (1996). Mirror effect in order and associative information: Role of response strategies. Journal of Experimental Psychology: Learning, Memory, \& Cognition, 22, 687-695.

HinRICHS, J. V. (1970). A two-process memory-strength theory for judgment of recency. Psychological Review, 77, 223-233.

HinRICHS, J. V., \& BUSCHKE, H. (1968). Judgment of recency under steady-state conditions. Journal of Experimental Psychology, 78, $574-$ 579.

Hintzman, D. L. (1988). Judgments of frequency and recognition memory in a multiple-trace memory model. Psychological Review, $\mathbf{9 5}$, 528-551.

HinTZMAN, D. L. (2000). Memory judgments. In E. Tulving \& F. I. M. Craik (Eds.), The Oxford handbook of memory (pp. 165-195). Oxford: Oxford University Press.

Hintzman, D. L. (2001). Judgments of frequency and recency: How they relate to reports of subjective awareness. Journal of Experimental Psychology: Learning, Memory, \& Cognition, 27, 1347-1358.

Hintzman, D. L. (2002). Context matching and judgments of recency. Psychonomic Bulletin \& Review, 9, 368-374.

Hintzman, D. L. (in press). Robert Hooke's model of memory. Psychonomic Bulletin \& Review.

Hintzman, D. L., Block, R. A., \& Summers, J. J. (1973). Contextual associations and memory for serial position. Journal of Experimental Psychology, 97, 220-229.

Hintzman, D. L., Caulton, D. A., \& Levitin, D. J. (1998). Retrieval dynamics in recognition and list discrimination: Further evidence of separate processes of familiarity and recall. Memory \& Cognition, 26, 449-462.

Hintzman, D. L., \& Waters, R. M. (1969). Interlist and retention intervals in list discrimination. Psychonomic Science, 17, 357-358.
Hooke, R. (1969). The posthumous works of Robert Hooke. New York: Johnson.

Keppel, G., \& Underwood, B. J. (1962). Proactive inhibition in shortterm retention of single items. Journal of Verbal Learning \& Verbal Behavior, 1, 153-161.

KincAid, J. P., \& Wickens, D. D. (1970). Temporal gradient of release from proactive inhibition. Journal of Experimental Psychology, 86, 313-316.

KuČERA, J., \& FrANCIS, W. N. (1967). Computational analysis of present day American English. Providence, RI: Brown University Press.

LoEss, H., \& WAUgh, N. C. (1967). Short-term memory and intertrial interval. Joural of Verbal Learning \& Verbal Behavior, 6, 455-460.

Maddox, W. T., \& Estes, W. K. (1997). Direct and indirect stimulusfrequency effects in recognition. Journal of Experimental Psychology: Learning, Memory, \& Cognition, 23, 539-559.

Mulligan, N. W. (2001). Word frequency and memory: Effects on absolute versus relative order memory and on item memory versus order memory. Memory \& Cognition, 29, 977-985.

MuRdock, B. B., JR. (1982). A theory for the storage and retrieval of item and associative information. Psychological Review, 89, 609-626.

Murdock, B. B., JR., \& Kahana, M. J. (1993a). Analysis of the liststrength effect. Journal of Experimental Psychology: Learning, Memory, \& Cognition, 19, 689-697.

Murdock, B. B., JR., \& KaHANA, M. J. (1993b). List-strength and listlength effects: Reply to Shiffrin, Ratcliff, Murnane, and Nobel (1993). Journal of Experimental Psychology: Learning, Memory, \& Cognition, 19, 1450-1453.

Murdock, B. B., JR., Smith, D., \& BAI, J. (2001). Judgments of frequency and recency in a distributed memory model. Journal of Mathematical Psychology, 45, 564-602.

Peterson, L. R. \& Gentile, A. (1965). Proactive interference as a function of time between tests. Journal of Experimental Psychology, 70, 473-478.

Ratcliff, R. (1978). A theory of memory retrieval. Psychological Review, 85, 59-108.

Ratcliff, R, Clark, S., \& SHIFFrin, R. (1990). The list-strength effect. I. Data and discussion. Journal of Experimental Psychology: Learning, Memory, \& Cognition, 16, 163-178.

Rosenthal, R., \& Rosnow, R. L. (1985). Contrast analysis. Cambridge: Cambridge University Press.

Shiffrin, R. M., RATClifF, R, \& Clark, S. (1990). The list-strength effect: II. Theoretical mechanisms. Journal of Experimental Psychology: Learning, Memory, \& Cognition, 16, 179-195.

Shiffrin, R. M., Ratcliff, R., Murnane, K., \& Nobel, P. (1993). TODAM and the list-strength and list-length effects: Comment on Murdock and Kahana (1993). Journal of Experimental Psychology: Learning, Memory, \& Cognition, 19, 1445-1449.

Shiffrin, R. M., \& Steyvers, M. (1997). A model for recognition memory: REM-retrieving effectively from memory. Psychonomic Bulletin \& Review, 4, 145-166.

WeLLS, E. J. (1974). Strength theory and judgments of recency and frequency. Journal of Verbal Learning \& Verbal Behavior, 13, 378-392.

YNTEMA, D. B., \& TRASK, F. P. (1963). Recall as a search process. Journal of Verbal Learning \& Verbal Behavior, 2, 65-74.

(Manuscript received April 26, 2002; manuscript accepted for publication August 23, 2002.) 